\title{
Fabrication of Water Cooler cum Air Conditioner
}

\author{
Sura Sankeerthan ${ }^{1}$ Samba Sai Karthik ${ }^{2}$ Pasurla Nandakishor Reddy ${ }^{3}$ \\ Dr. V.V. Prathibhabharathi ${ }^{4}$ \\ 12,3, Students of Mechanical Department ,4 Professor of Mechanical Department
}

\begin{abstract}
This project "WATER COOLER CUM AIR CONDITIONER SYSTEM" makes the study of the development of a water cooling system using a normal air conditioner. The main aim behind developing this device is to develop a multifunctional unit which can provide cold water along with regular air conditioning cycle. The refrigerant is used as the medium which absorbs and removes heat from the space to be cooled and subsequently rejects that heat elsewhere. This heat of the refrigerant is used to cool the water, which can be then used for drinking purposes. The air cycle is the conventional vapor compression cycle.
\end{abstract}

\section{Introduction}

Any substance capable of absorbing heat from another required substance can be used as refrigerant i.e. ice, water, air or brine. A mechanical refrigerant is a refrigerant which will absorb the heat from the source and dissipate the same to the sink or in the form of latent heat. The physical properties will enable them to repeat continuously a liquid to gas and gas to liquid transformation. Air was used as a refrigerant in many refrigerant system in olden days considering as safest refrigerant. Ammonia, carbon dioxide and sulphur dioxide were used for domestic and commercial purposes until ferons were available. The refrigerants are classified in to two groups:

1. Primary refrigerants

2. Secondary refrigerants

Primary refrigerants directly take the part in the refrigerants system where secondary refrigerants are first cooled with the help of the primary refrigerants and are further used for cooling purpose.

\section{COMPONENTS}

- Compressor

$>$ Working Pressure (minimum) $9 \mathrm{Kg}$. / Sq. Cm.

$>$ No. of stages One (or more)

$>$ Motor Power $200 \mathrm{KW}$ (or more)

$>$ Operating Voltage 3 Phase, 415 V

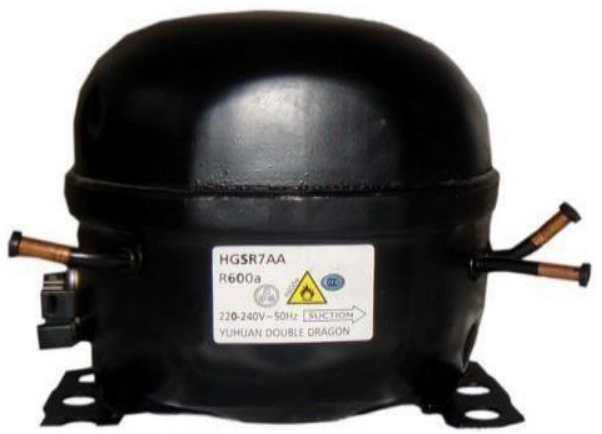

- Condenser

$>$ Air condenser used in the residential and small offices applications

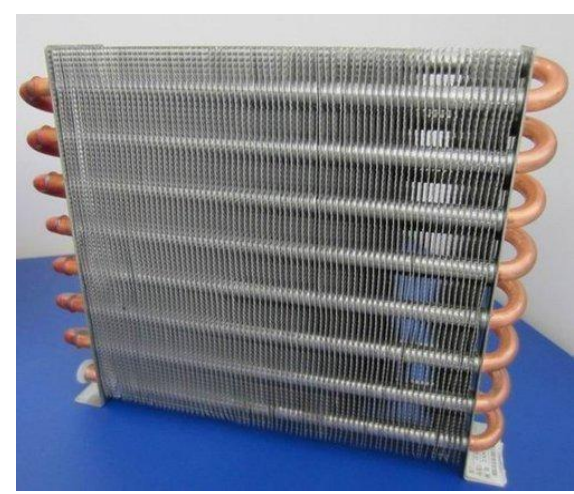

- Expansion valve

$>$ In this process we use the Thermostatic expansion valves.

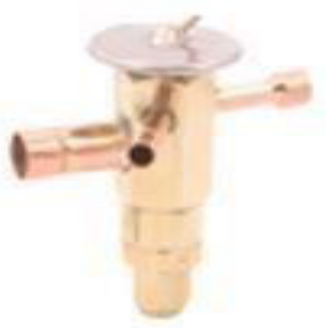

- Evaporator

$>$ Power supply $230 \mathrm{~V}, \mathrm{AC}, 50 \mathrm{~Hz}$

$>$ Temperature accuracy $\pm 2{ }^{\circ} \mathrm{C}$

$>$ Condenser support Yes 


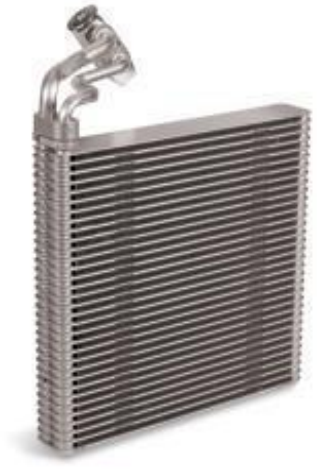

- Water tank

$>$ The size of the water tank is 10 liters.

$>$ It is non-corrosive.

$>$ Two taps are connected

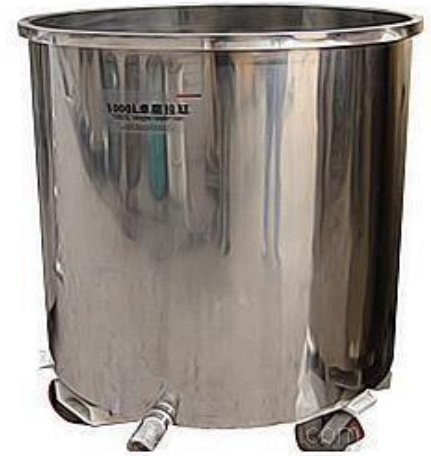

- Outdoor unit

$>$ Nominal Capacity: 1 ton

$>$ Electricity in put: $230 \mathrm{~V} / 50 \mathrm{~Hz} /$ Single Phase

$>$ Outdoor unit: Less than $55 \mathrm{~dB}$

$>$ Compressor: rotary type

$>$ Body surface finish: powder coated/high quality paint finish

$>$ Air filtering unit: Activated carbon cartridge, dust proof and anti-bacteria filter

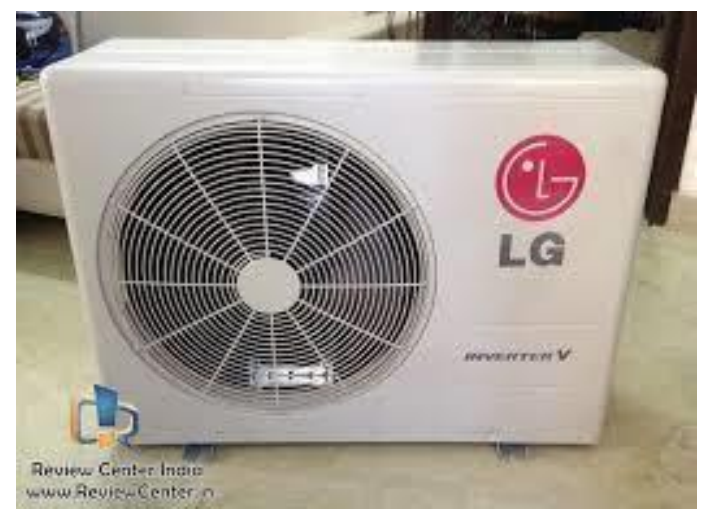

$>$ Supply voltage 230 volts

$>$ Rated speed $900 \mathrm{rpm}$

$>$ Rated frequency $45 \mathrm{~Hz}$

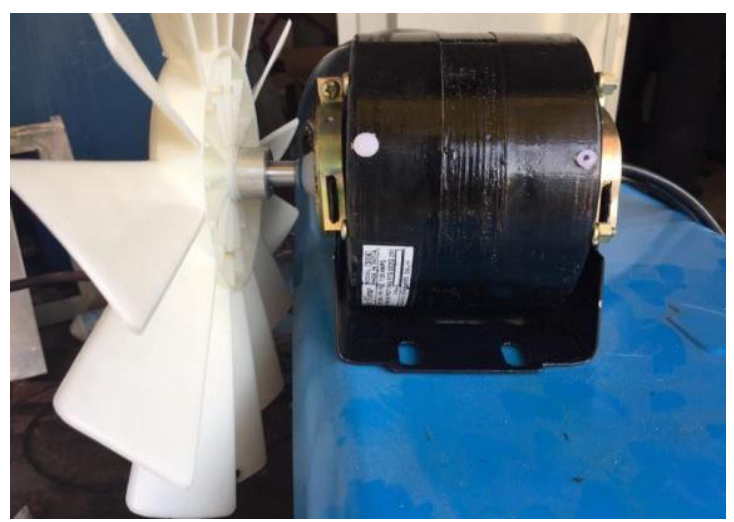

\section{Working}

- There is a sequence of operations in the experiment the refrigerant we used in this experiment is F-22 it also called as R-22 the chemical formula is $C H C L F 2$.

- This refrigerant compressed in the centrifugal compressor where the friction is less since there is no sliding parts in it. There is no vibrations in these types of compressor. It compresses the refrigerant, to increase the pressure of the refrigerant which makes the refrigerant to pass all over the system.

- The F-22 refrigerant is compressed more than the remaining refrigerants. The process is based on vapour compression refrigeration cycle. The refrigerant is compressed in compressor and then moves into condenser where the heat is absorbed, then, from the condenser it moves into expansion valve where the refrigerant is going to expand.

- The phase of the refrigerant changes in this process from vapour state to liquid state. From the expansion valve it enters to evaporator and phase change occurs from liquid state to vapour state. Than the refrigerant is surrounded.

- The copper tube is surrounded to water tank through which the refrigerant passes. It utilizes the $25 \%$ of the refrigerant to cool the water and the remaining $75 \%$ of the refrigerant effect utilized by the air conditioner where the refrigerant passes through the cooling coil.

- The motor fan is placed back of the coiling coil which blows the air and gives cooling effect. Then the refrigerant goes in to the outdoor unit. This cycle keeps on continuing and it makes 50 cycles per minute.

- Motor

$>$ Rated power 3hp 


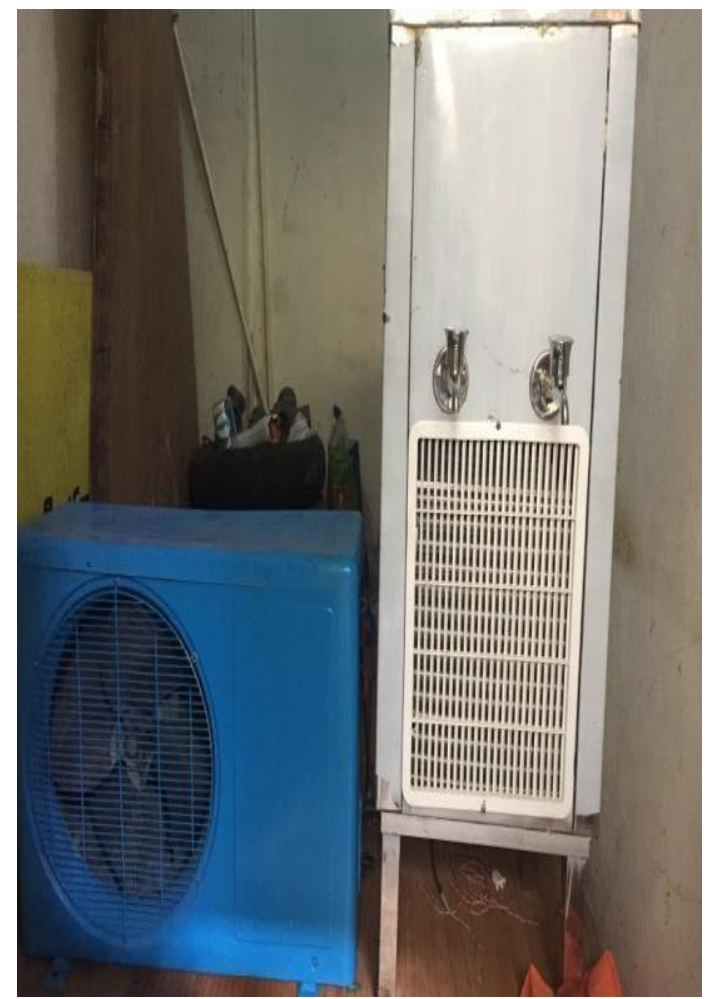

Water cooler cum air conditioner

\section{Conclusion}

- By using a water cooler and air cooler as a room cooler you can save $80 \%$ of the energy consumed by a 1.5 ton wall AC. Besides, this experiment can be used in cooling rooms, offices and halls and also cools water becomes a universally accepted option in India too.

- Depending on specific situations, this run parallel to, compete with or even replace air conditioning system. When that happens the cost of water cooling and air conditioning devices will come down dramatically.

- On the basis of this experiment I have found that a water cooler that cools ten liters of water down to $8 \mathrm{C}$ in an hour can be an ideal room cooler to bring the temperature of room air by $18 \mathrm{C}$ for a room of about 12 sq. feet.

- The sag is that for the present a water cooler of that capacity could cost a packet, about Rs.12,000 and its air conditioning attachment another Rs.20,000. In a specially made design the combined unit should not cost more than Rs.18,000. Since its running cost in terms of power used is only $10 \%$ of the wall $\mathrm{AC}$, the common man would prefer it any day. 